\title{
Surto de intoxicação por sal em suínos em Santa Catarina ${ }^{1}$
}

\author{
Gisele S. Boos², Tatiane T.N. Watanabe², Paula R. Almeida², Luiz G.S. Oliveira², \\ Saulo P. Pavarini ${ }^{2}$, Priscila Zlotowski ${ }^{2}$ e David Driemeier ${ }^{2 *}$
}

\begin{abstract}
Boos G.S., Watanabe T.T.N., Almeida P.R., Oliveira L.G.S., Pavarini S.P., Zlotowski P. \& Driemeier D. 2012. [Outbreak of salt poisoning in pigs in Santa Catarina.] Surto de intoxicação por sal em suínos em Santa Catarina. Pesquisa Veterinária Brasileira 32(4):329-332. Setor de Patologia Veterinária, Faculdade de Veterinária, Universidade Federal do Rio Grande do Sul, Av. Bento Gonçalves 9090, Porto Alegre, RS 91540-000, Brazil. E-mail: davetpat@ufrgs.br

A total of 70 pigs were affected and died due to salt poisoning in two farms in southern Brazil. The only source of drinking water available to the pigs was whey from cheese salting process. One day after receiving the whey, animals started getting sick and showed excessive salivation, opisthotonus, paddling, and cyclic tremors. At necropsy of three pigs, two of them presented flattening of gyri and the other one presented cortical telencephalon edema. Microscopically, severe diffuse neuronal necrosis in telencephalic laminar cortex, Alzheimer type II astrocytes (AIIA), eosinophilic and lymphocytic perivascular cuffing apart of perivascular edema were observed. Weak or absent anti-glial fibrillary acidic protein (GFAP) immunolabeling was associated with positive immunostaining for S-100 in AIIA cytoplasm. Concentration of sodium in serum and liquor samples from dead pigs resulted 140 and $156 \mathrm{mmol} / \mathrm{L}$, respectively.
\end{abstract}

INDEX TERMS: Pigs, salt poisoning, sodium chloride, neuronal necrosis.

RESUMO-- Descreve-se a ocorrência de surto de intoxicação por sal em suínos de duas propriedades, onde 70 porcos morreram. Soro de leite proveniente da salga de queijo era servido no cocho como única fonte hídrica aos animais. Não havia bebedouros nas instalações. Um dia após o fornecimento do soro, os porcos começaram a adoecer e apresentaram salivação excessiva, movimentos de pedalagem, opistótono e tremores cíclicos. Na necropsia, dois suínos apresentaram achatamento das circunvoluções do córtex telencefálico e um outro, edema no córtex telencefálico. $\mathrm{Na}$ histopatologia, observou-se necrose neuronal laminar difusa acentuada no córtex telencefálico, astrócitos de Alzheimer tipo II (AIIA), infiltrado multifocal perivascular de eosinófilos e linfócitos e edema perivascular. Outros achados incluíram marcação imuno-histoquímica fraca ou ausente para proteína glial fibrilar ácida (GFAP), mas intensa marcação positiva no citoplasma dos AIIA para S-100. As concen-

\footnotetext{
${ }^{1}$ Recebido em 18 de novembro de 2011.

Aceito para publicação em 9 de dezembro de 2011.

${ }^{2}$ Setor de Patologia Veterinária, Faculdade de Veterinária, Universidade Federal do Rio Grande do Sul (UFRGS), Avenida Bento Gonçalves 9090, Agronomia, Porto Alegre, RS 91540-000, Brasil. *Autor para correspondência: davetpat@ufrgs.br
}

trações de sódio sérico e do líquor mensuradas nos porcos estudados foram de 140 e $156 \mathrm{mmol} / \mathrm{L}$, respectivamente.

TERMOS DE INDEXAÇÃO: Suínos, intoxicação por sal, cloreto de sódio, necrose neuronal.

\section{INTRODUÇÃO}

A toxicose pelo íon sódio é um problema comum na criação de suínos e, ocasionalmente pode ocorrer em bovinos, equinos e cães (Summers et al. 1995). A doença é mais comumente observada em casos de ingestão excessiva de cloreto de sódio, ou pela ingestão de concentrações normais de cloreto de sódio em associação com insuficiente aporte hídrico (Summers et al. 1995). A doença também pode estar relacionada a outros aspectos de manejo (Carson 2006) como a mudança de bebedouros (Moreno et al. 2007), ou a criação de suínos com sobras industriais como o soro de leite da fabricação de queijos (Carson 2006, Moreno et al. 2007). 0 nível máximo tolerado por suínos é de $3,14 \%$ de sódio, ou $8 \%$ de cloreto de sódio $(\mathrm{NaCl})$ na ração. A dose tóxica é $2,2 \mathrm{~g} / \mathrm{kg}$ de peso vivo (Radostits et al. 2000) e animais de 1 a 4 meses de idade são mais suscetíveis à intoxicação (Summers et al. 1995, Cockcroft \& Jackson 2007). 
A doença se caracteriza, clinicamente, por alterações neurológicas que afetam de forma repentina grande parte dos animais de um mesmo lote. A patogênese da intoxicação, até o momento, não está totalmente elucidada. Altos níveis de sódio no cérebro causam hiperosmolaridade e influxo de eletrólitos para o tecido encefálico (Casteel \& Cowart 2001, Zachary 2009). Quando há uma reidratação rápida, o excesso de íons sódio intracelular é transportado, ativamente, junto com íons potássio e cloreto do citoplasma neuronal para a circulação sanguínea (Zachary 2009). A água consumida é drenada para o sistema nervoso central (SNC) por pressão osmótica causando aumento de volume e edema cerebral (Casteel \& Cowart 2001). Este trabalho descreve os achados clínicos, patológicos e imuno-histoquímicos registrados em dois surtos de intoxicação por sal em suínos de terminação, no estado de Santa Catarina - Brasil.

\section{MATERIAL E MÉTODOS}

Em duas granjas comerciais de suínos de terminação, cujos rebanhos somavam 1500 suínos, localizadas na região oeste de Santa Catarina, morreram 70 suínos, após apresentarem sinais neurológicos. Dados epidemiológicos e sinais clínicos da enfermidade foram obtidos em visitas às propriedades. Foram necropsiados três suínos (Suínos 1, 2 e 3) de uma propriedade e fragmentos de diversos órgãos foram coletados e fixados em solução formalina a $10 \%$ para processamento pelas técnicas de rotina histológica e subsequente coloração em hematoxilina-eosina (HE). Realizou-se a dosagem de sódio no líquor de dois suínos (Suínos 1 e 2). Na segunda propriedade visitada, os casos já haviam sido controlados.

Amostras foram submetidas à técnica de imuno-histoquímica (IHQ) pelo método estreptavidina-biotina ligada à peroxidase. 0 bloqueio da atividade da peroxidase endógena foi realizado com a incubação dos cortes dos tecidos em solução $10 \%$ de peróxido de hidrogênio (30 vol.), em metanol, durante 15 minutos. Para a recuperação antigênica, utilizou-se tampão tris EDTA, pH 9,0 e tampão citrato, $\mathrm{pH} \mathrm{6,0} \mathrm{em} \mathrm{panela} \mathrm{de} \mathrm{pressão} \mathrm{a} 96^{\circ} \mathrm{C}$, por $40 \mathrm{minu}-$ tos (anticorpo policlonal anti-proteína ácida fibrilar glial - GFAP, Z0334, DakoCytomation e anticorpo policlonal anti-proteína S-100, Z0311, DakoCytomation, respectivamente). Os anticorpos primários para GFAP e S-100 foram diluídos em 1:500 e 1:200, respectivamente, em solução salina tamponada com fosfato (PBS), aplicados nas lâminas e incubadas em câmara úmida durante o período de 14-16 horas (overnight), a 4ํㅡ. Após, os cortes foram incubados com anticorpo secundário biotinilado ligado a estreptavidina-peroxidase (kit LSAB-HRP, K0690, DakoCytomation), 20 minutos cada etapa. A reação para GFAP foi revelada com 3,3-diaminobenzidina (DAB, DakoCytomation) e, para S-100, o cromógeno foi vermelho VECTOR NovaRed. Como contracorante, utilizou-se hematoxilina de Mayer seguida de montagem em meio aquoso (S1964, DakoCytomation). Como controle positivo, utilizou-se corte histológico de encéfalo para GFAP e de schwannoma para S-100. Como controle negativo, incubou-se corte de córtex telencefálico de um dos suínos afetados com PBS ao invés do anticorpo primário.

\section{RESULTADOS}

Nas duas granjas, o soro de leite era rotineiramente usado. 0 problema aconteceu quando o soro de leite com resíduo da salga de queijo foi servido no cocho como única fonte hídrica para os suínos. 0 soro de leite usado da dieta era proveniente de um mesmo fornecedor, que relatou que a concentração de $\mathrm{NaCl}$ no soro era $2 \%$. Um dia após inclusão do soro com salga a $2 \%$ na dieta dos suínos, estes começaram a apresentar salivação excessiva, movimentos de pedalagem, opistótono, tremores cíclicos, convulsões intermitentes com intervalos regulares entre as crises, decúbito lateral com movimentos de pedalagem, permaneciam sentados ou em decúbito esternal pressionado a cabeça contra a parede ou o cocho (Fig.1). Outros se mantinham em decúbito lateral ou esternal e não respondiam a estímulos externos (Fig.2). Na necropsia, observou-se, em dois suínos, achatamento das circunvoluções do córtex telencefálico (Fig.3) e, em um suíno, edema no córtex telencefálico. As concentrações de sódio sérico e do líquor mensuradas dos Suínos 1 e 2 foram de 140 e 156mmol/L respectivamente.

$\mathrm{Na}$ avaliação microscópica, o córtex telencefálico apresentou necrose neuronal laminar difusa acentuada, caracterizada por neurônios encolhidos com citoplasma vermelho, núcleos picnóticos, ou ausentes. Intenso edema perineuronal (Fig.4 e 5) e astrócitos tumefeitos com cromatina dispersa, bordos citoplasmáticos indistintos, muitas vezes formando grupos de duas ou mais células (Alzheimer tipo II (AIIA)), na substância cinzenta (Fig.6). Também foi observado discreto infiltrado multifocal perivascular de eosinófi-

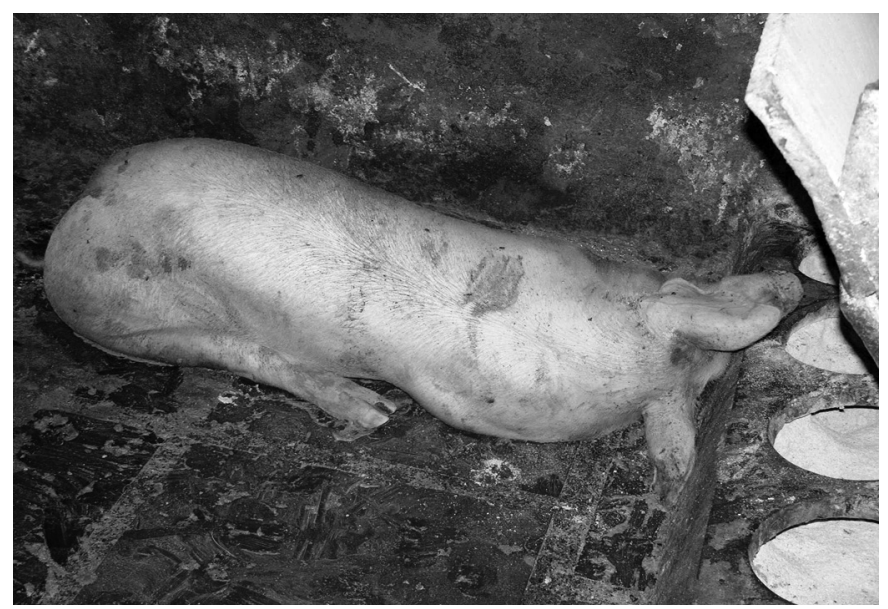

Fig.1. Suíno intoxicado por sal em decúbito, pressionando a cabeça contra o cocho.

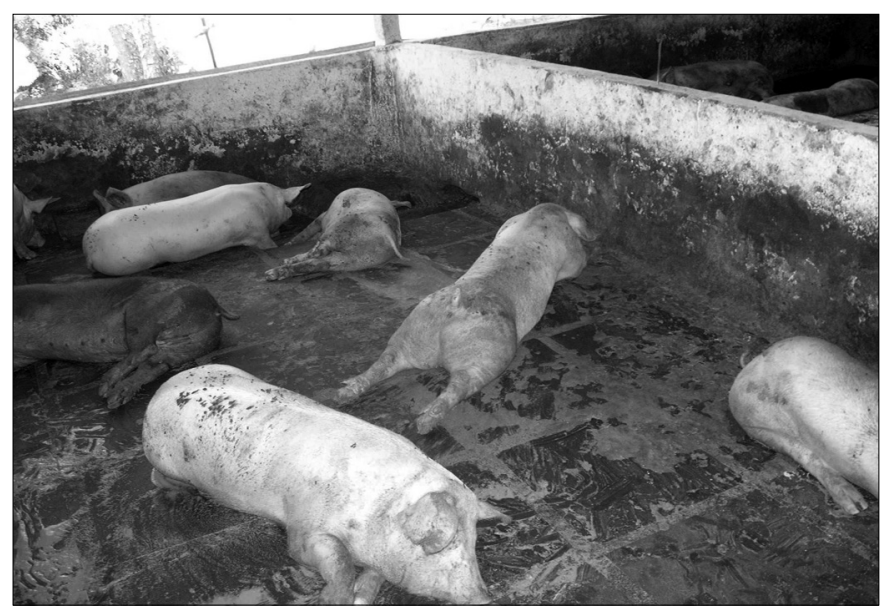

Fig.2. Suínos intoxicados por sal, animais caídos com apatia. 


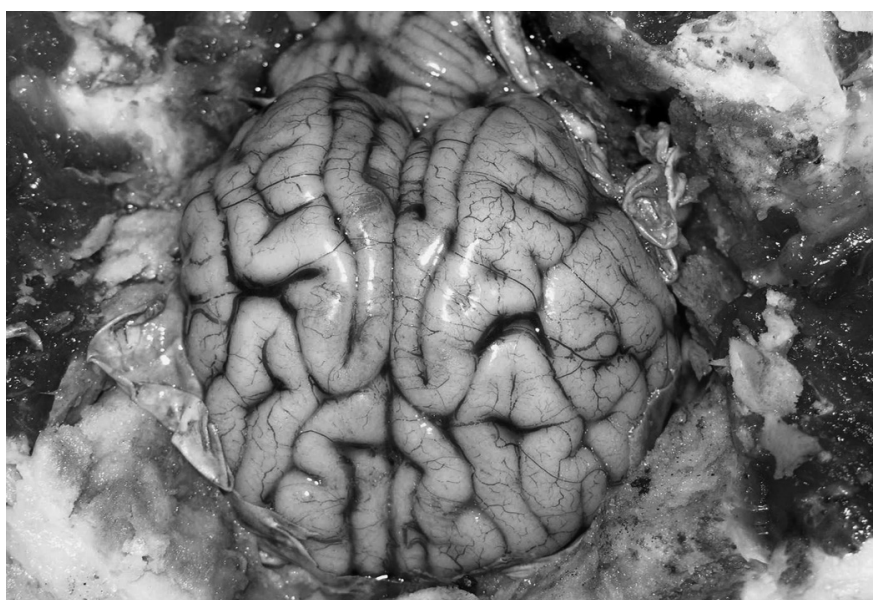

Fig.3. Achatamento das circunvoluções telencefálicas, em suíno intoxicado por sal.

los e linfócitos (Fig.7), vasos capilares encefálicos evidentes com edema perivascular acentuado, discreta hemorragia e tumefação dos núcleos das células endoteliais. Congestão e degeneração gordurosa leve foram observadas no fígado de
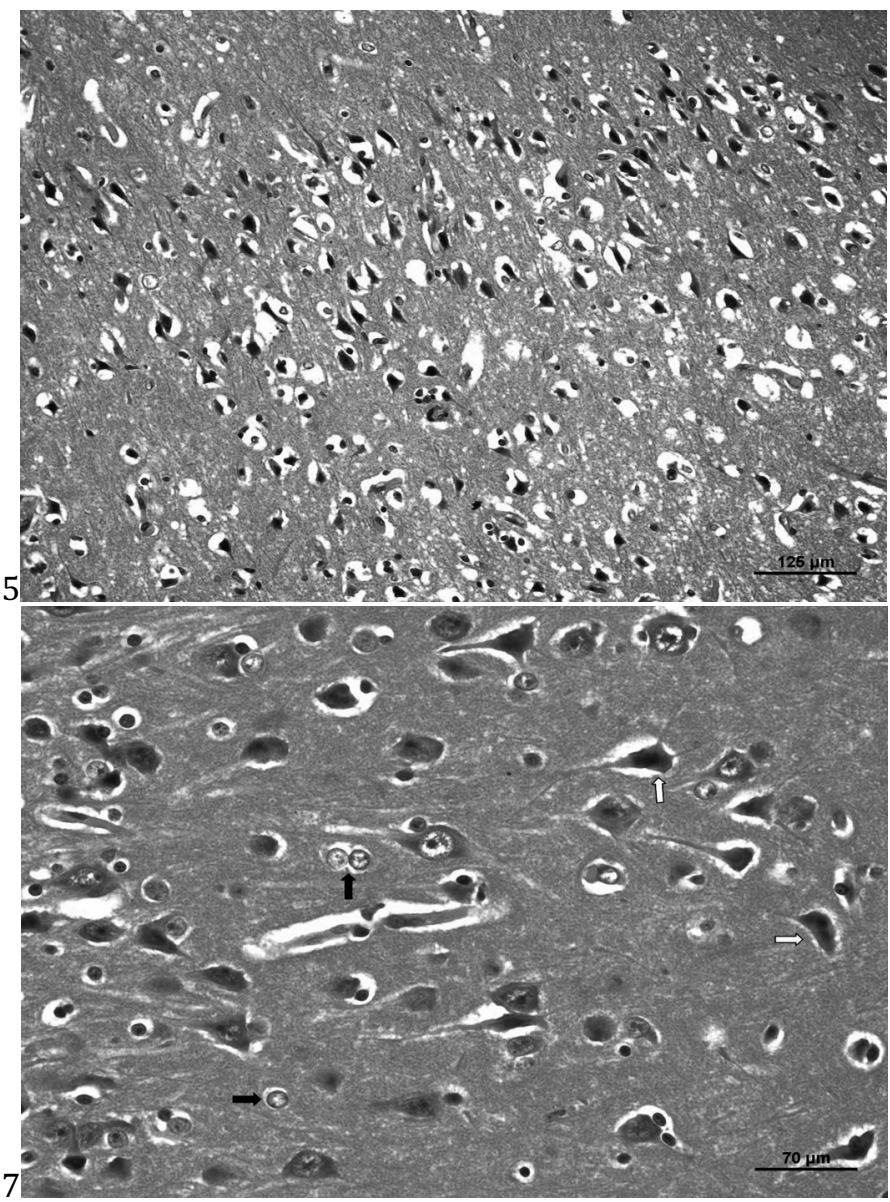

Fig.5. Necrose neuronal laminar e edema perineural intensos no córtex telencefálico, em suíno intoxicado por sal. HE, obj.20x.

Fig.7. Astrócitos de Alzheimer tipo II (setas pretas) e neurônios necróticos (setas brancas) em córtex telencefálico, em suíno intoxicado por sal. HE, obj.40x.

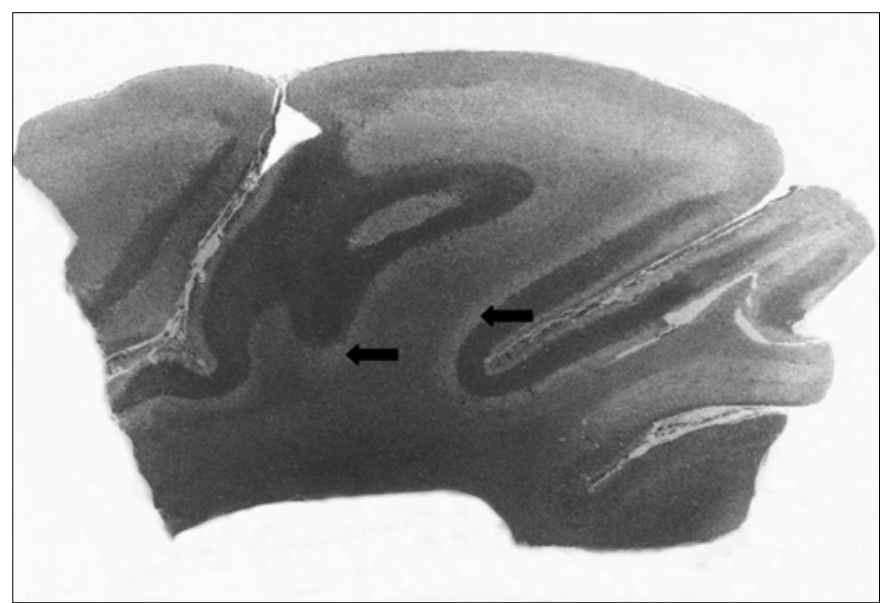

Fig.4. Imagem submacroscópica do corte histológico do córtex telencefálico com intenso edema na substancia cinzenta (seta), de suíno intoxicado por sal.

um dos suínos. Os demais órgãos não apresentavam alterações histológicas. Na IHQ houve marcação fraca ou ausente para GFAP nos AIIA, mas também intensa marcação para S-100 no núcleo e no citoplasma dos AIIA (Fig. 8).
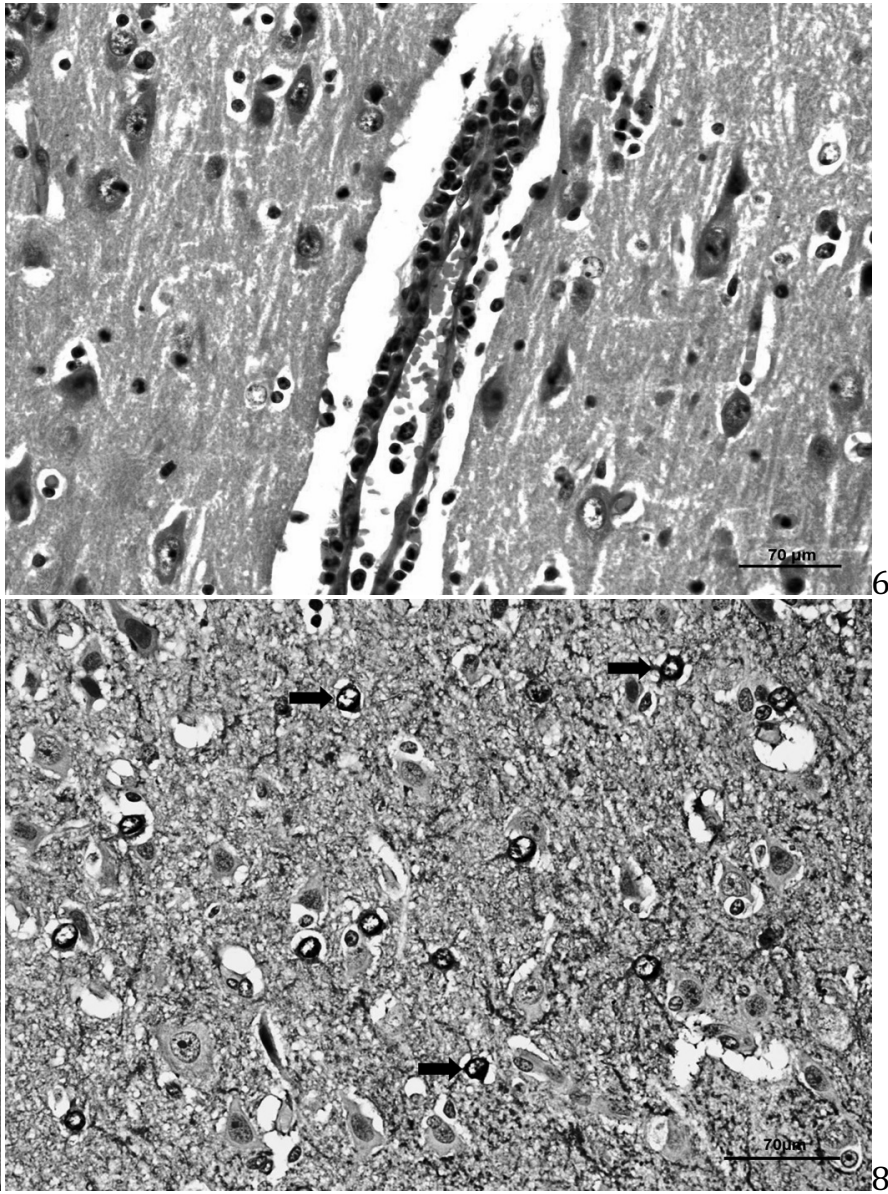

Fig.6. Infiltrado perivascular leve de eosinófilos, em suíno intoxicado por sal. HE, obj.40x.

Fig.8. Imuno-histoquímica no corte telencefálico de um suíno intoxicado por sal, marcação positiva em astrócitos de Alzheimer tipo II. Anticorpo anti-S-100. Método estreptavidina-biotina ligada à peroxidase, cromógeno Vector Nova Red, obj.40x. 


\section{DISCUSSÃO}

O soro de leite representa uma alternativa alimentar para os suínos, devido ao seu valor nutricional e baixo custo de produção (Martins et al. 2008). A quantidade de sal presente na dieta de suínos pode variar consideravelmente, porém a toxicidade não ocorrerá se houver disponibilidade satisfatória de água (Maxie \& Youssef 2007). Os valores normais da concentração de sódio sérico estão entre 135 e $150 \mathrm{mEq} / \mathrm{L}$ (Carlson 1989). Em animais que consumiram sódio em excesso, ou que têm baixa disponibilidade de água, os níveis séricos do íon estarão consideravelmente acima do normal durante o estágio severo da intoxicação (Radostits et al. 2007); entretanto, após a reidratação, esses valores tendem a retornar (Carson 2006), ou ficar abaixo do normal (Carlson 1989).

De acordo com Jackson e Cockroft (2007), os sinais clínicos desenvolvidos durante a toxicose estão relacionados ao SNC. As convulsões são sinais característicos quanto a seus padrões e regularidade de intervalos em que ocorrem (Radostits et al. 2007). Sugere-se que os tremores cíclicos e olhar fixo são sinais que geralmente evoluem para esse quadro (Maxie \& Youssef 2007). As convulsões iniciam como tremores do focinho (Radostits et al. 2007) e rapidamente se estendem como espasmos clônicos da musculatura longa do pescoço causando opistótono, o que faz com que o animal recue e sente (Maxie \& Youssef 2007, Radostits et al. 2007).

À necropsia, as lesões encontradas são inespecíficas e incluem congestão cerebral e leptomeningeal, edema e achatamento das circunvoluções (Summers et al. 1995, Zachary 2007). A patogênese das lesões cerebrais na intoxicação por sal em suínos é pouco compreendida; no entanto, o edema cerebral agudo é, provavelmente, produzido pela correção osmótica necessária pelo aumento dos níveis de sal no cérebro, quando a água é disponibilizada após restrição temporária (Finnie et al. 2010).

Histologicamente, as alterações observadas foram semelhantes às descritas por Brito et al. (2001), que descreveram a ocorrência de edema cerebral agudo, evidenciado pelo aumento do espaço de Virchow-Robin que caracteriza uma intoxicação aguda (Radostits et al. 2007). A tendência dos eosinófilos infiltrarem as meninges e os espaços perivasculares do cérebro de suínos é frequentemente relacionada com o consumo de quantidades excessivas de sódio e é mais comum em casos agudos (Summers et al. 1995). Entretanto, em suínos que sobrevivem por alguns dias, a eosinofilia perivascular pode desaparecer, ou ser substituída por infiltrado de células mononucleares (Carson 2006). 0 infiltrado eosinofílico também pode ocorrer em outras afecções de suínos, como na leucomalácia da doença do coração de amora; enquanto que as lesões degenerativas observadas na intoxicação por sódio são idênticas às observadas em outras formas de privação de energia (hipóxia, deficiência de tiamina) (Summers et al. 1995). 0 diagnóstico diferencial de outras doenças com similaridades clínicas, como a doença de Aujeszky, circovirose, meningite estreptococócica e doença do edema deve ser averiguado; entretanto, os achados anatomopatológicos são distintos entre essas enfermidades (Maxie \& Youssef 2007, Radostits et al. 2007).

Nos animais afetados, a necrose neuronal cerebrocortical laminar é, frequentemente, acompanhada por tumefa- ção astrocítica (Summers et al. 1995, Zachary 2007). Finnie et al. (2010) identificaram inúmeros AIIA por todo o cérebro, distribuídos de forma randômica pela área cinzenta da região cerebrocortical. Essas células foram caracterizadas por núcleos tumefeitos, claros e vacuolizados, com pouca cromatina marginada na periferia (Finnie et al. 2010).

À semelhança do que foi descrito por outros autores (Summers et al. 1995, Finnie et al. 2010, Bandarra et al. 2010), no presente estudo, AIIA demonstraram marcação fraca para GFAP e intensa para S-100. AIIA, geralmente, não marcam para GFAP, provavelmente, devido à instabilidade do mRNA da GFAP que causa perda desse filamento intermediário (Norenberg 1994). Com isso, sugere-se que a intoxicação por sal determine perda seletiva dos filamentos de GFAP, o que não é comum, já que astrocitose reativa é, invariavelmente, associada com aumento de filamento citoplasmático (Summers et al. 1995, Zachary 2007, Sant'ana et al. 2009).

Agradecimentos.- Ao Conselho Nacional de Desenvolvimento Científico e Tecnológico (CNPQ) e à Coordenação de Aperfeiçoamento de pessoal de Nível Superior (CAPES) pela concessão de bolsas de mestrado e pós-doutorado. Agradecemos ao Eduardo Conceição de Oliveira e ao Prof. Cláudio Estêvão Farias Cruz pelas sugestões.

\section{REFERÊNCIAS}

Bandarra P.M, Pavarini S.P., Raymundo D.L., Corrêa A.M.R., Pedroso P.M.O \& Driemeier D. 2010. Trema micrantha toxicity in horses in Brazil. Equine Vet. J. 42(5):456-459.

Brito L.A.B., Matos M.P.C., Sobestiansky J., Sucupira M.C.A \& Ortolani E.L. 2001. Accumulative sodium poisoning in Brazilian swine fed whey. Vet. Human Toxicol. 43(2):88-90.

Carson T.L. 2006. Toxic minerals, chemicals, plants, and gases, p.971-984. In: Straw B.E., Zimmerman J.J., D’Allaire S. \& Taylor D.J. (Eds), Diseases of Swine. $9^{\text {th }}$. ed. Wiley-Blackwell Publishing, Oxford. 1153 p.

Carlson G.P. 1989. Fluid, electrolyte, and acid-base balance, p.543-575. In: Kaneco, J.J. (Ed.), Clinical Biochemistry of Domestic Animals. $4^{\text {th }}$ ed. Academic Press, London. 932p.

Cowart R.P. \& Casteel S.W. 2001. An Outline of Swine Diseases: A handbook. $2^{\text {nd }}$ ed. Iowa State University Press, Ames, p.111-112.

Finnie J.W., Blumbergs P.C. \& Williamson M.M. 2010. Alzheimer type II astrocytes in the brains of pigs with salt poisoning (water deprivation/ intoxication). Aust. Vet. J. 88:405-407.

Jackson P.G.G. \& Cockcroft P.D. 2007. Handbook of Pig Medicine. Saunders Elsevier, Philadelphia, p.140.

Martins T.D.D., Pimenta Filho E.C., Costa R.G. \& Souza J.H.M. 2008. Soro de queijo líquido na alimentação de suínos em crescimento. Revta Ciênc. Agr., Fortaleza, 39(2):301-307.

Maxie M.G. \& Youssef S. 2007. Nervous system, p.281-457. In: Maxie M.G. (Ed.), Jubb, Kennedy and Palmer's Pathology of Domestic Animals. Vol.1. $5^{\text {th }}$ ed. Saunders Elsevier, Philadelphia. 1229p.

Moreno A.M., Sobestiansky J. \& Morés N. 2007. Intoxicação por minerais, produtos químicos, plantas e gases, p.466-468. In: Sobestiansky J. \& Barcellos D. (Eds), Doenças dos Suínos. Cânone Editora, Goiânia.

Norenberg M.D. 1994. Astrocytic response to CNS injury. J. Neuropathol. Exp. Neurol. 53:213-220.

Radostits O.M., Gay C.C., Hinchcliff K.W. \& Constable P.D. 2007. Veterinary Medicine: a textbook of diseases of cattle, horses, sheep, pigs, and goats. $10^{\text {th }}$ ed. Saunders Elsevier, Philadelphia. 2156p.

Sant'ana F.J.F., Rissi D.R., Lucena R.B., Lemos R.A.A., Nogueira A.P.A. \& Barros C.S.L. 2009. Polioencefalomalacia em bovinos: epidemiologia, sinais clínicos e distribuição das lesões no encéfalo. Pesq. Vet. Bras. 29(7):487-497.

Summers B.A., Cummings J.F. \& deLahunta A. 1995. Veterinary Neuropathology. Mosby-Year Book, St Louis, p.254-255.

Zachary J.F. 2007. Nervous system, p.833-971. In: McGavin M.D. \& Zachary J.F. (Eds), Pathologic Basis of Veterinary Disease. $4^{\text {th }}$ ed. Mosby Elsevier, St Louis. 1476 p. 